\title{
Incidence of infection with hepatitis B virus in 56 patients with haemophilia A 1971-1979
}

\author{
ML STIRLING, JA MURRAY, P MACKAY, ${ }^{*}$ SH BLACK, ${ }^{*}$ JF PEUTHERER, ${ }^{*}$ CA LUDLAM \\ From the Department of Haematology, Royal Infirmary, and the *Hepatitis Reference Laboratory, \\ Department of Bacteriology, Medical School, Edinburgh.
}

SUMMARY During each of the four-year periods 1971-1975 and 1975-1979, the annual incidence of hepatitis B infection has been assessed in 56 patients with haemophilia $\mathrm{A}$ by measuring plasma HBsAg, anti-HBs and anti-HBc levels. Infection rates of $7 \%$ and $9.5 \%$ per annum respectively were observed for each four-year period despite the screening of individual blood donations for HBsAg by techniques up to the sensitivity of reversed passive haemagglutination. The highest incidence of seroconversion was amongst severe haemophiliacs many of whom had received treatment predominantly with cryoprecipitate. Of the 16 patients in whom serological evidence of hepatitis B infection was obtained only one had an accompanying clinical episode of hepatitis. We conclude that haemophiliacs are still at high risk of infection by hepatitis $B$ virus despite the screening of individual blood donors for HBsAg.

Despite the development of techniques for screening individual blood donations for evidence of hepatitis B infectivity it is clear that haemophiliacs are still at risk of developing hepatitis. Whilst some episodes of hepatitis may be related to non A non B viruses, others are clearly related to hepatitis $B$ virus (HBV) and these may be asymptomatic particularly in patients with severe haemophilia who receive large quantities of transfused blood products. ${ }^{1-4}$ During the period of this study from 1971 to 1979 two changes have taken place which might influence the rate of hepatitis $B$ infection in haemophiliacs. The development of more sensitive tests to screen individual blood donations for $\mathrm{HBs} \mathrm{Ag}$ has led to a reduction in post transfusion hepatitis $B$ in nonhaemophiliac patients during the past 10 years. ${ }^{5}$ It might be anticipated, therefore, that patients with haemophilia would also demonstrate a reduced frequency of infection. Mitigating against such a reduction, however, is the gradual change from the use of cryoprecipitate to factor VIII concentrate. Whereas each unit of cryoprecipitate is derived from a single blood donation each bottle of factor VIII concentrate is made from a pool of several hundred or thousand donations and therefore has a much greater likelihood of containing infective viral contamination. ${ }^{67}$ The study reported in this communication is

Accepted for publication 15 December 1982 a sequel to a previous study of Edinburgh patients in which the HBV infection rate was $36 \%$ of patients at risk over the four-year period $1971-1975 .^{8}$ To follow up this study we not only collected further blood samples in 1979 from haemophiliacs but we have retested deep frozen serum samples from the same patients from 1971 and 1975, for anti-HBs and also anti-HBc, by radioimmunoassay. In addition to the original patients studied in 1971-75 we have examined sera from additional patients in the period 1975-79. The testing of all serum samples from each patient collected on different occasions in a single assay makes it easier to determine whether an individual patient has been infected by hepatitis B during the period of study.

\section{Patients and methods}

\section{PATIENTS}

The total number of haemophilia A patients of varying degrees of severity was 56 (Table 1). All patients had received blood products prior to 1971 . Serum samples were available for the whole period of study from 42 patients. Eleven additional haemophiliacs were studied 1971-1975 and four other individuals were included in the period 1975-1979. Therapy for these haemophiliacs was "on demand" and during the initial period of study was predominantly by cryoprecipitate although during the later period of 
Table 1 Patients studied 1971-75

\begin{tabular}{|c|c|c|c|c|c|}
\hline \multirow[t]{2}{*}{ Category } & \multirow[t]{2}{*}{ No } & \multicolumn{3}{|c|}{ Severity of haemophilia } & \multirow[t]{2}{*}{ Mean age (yr) (range) } \\
\hline & & Severe & Moderate & Mild & \\
\hline $\begin{array}{l}1 \text { Infected before } 1971 \\
2 \text { Seroconverted } \\
3 \text { No evidence of infection }\end{array}$ & $\begin{array}{r}24 \\
81\end{array}$ & $\begin{array}{l}18 \\
7 \\
8\end{array}$ & $\begin{array}{l}3 \\
1 \\
5\end{array}$ & $\frac{3}{8}$ & $\begin{array}{lr}25 \cdot 5 & (12-44) \\
13 & (5-19) \\
22 & (3-53)\end{array}$ \\
\hline
\end{tabular}

investigation factor VIII concentrate (Scottish National Blood Transfusion Service) was given increasingly to patients.

\section{SERUM SAMPLES}

These were collected during 1971, 1975 and 1979 and stored at $-20^{\circ} \mathrm{C}$.

\section{TESTS FOR HEPATITIS B INFECTION}

When received patients' sera were screened for hepatitis B surface antigen ( $\mathrm{HBsAg}$ ) by reverse passive haemagglutination. ${ }^{9}$ All sera were tested later in parallel for antibody to $\mathrm{HBsAg}$ (anti-HBs) by radioimmunoprecipitation, ${ }^{10}$ and for antibody to hepatitis B core antigen (anti-HBc) by a commercial assay (Corab, Abbott) or a radioimmunoassay using HBcAg produced in E. coli. ${ }^{11}$ At the Scottish Regional Blood Transfusion Centres individual blood donations were tested for HBsAg by techniques up to the sensitivity of reversed passive haemagglutination.

\section{Results}

The results of the anti-HBs assay can be scored as weak, moderate and strong, corresponding to $0 \cdot 01$, 0.1 and $1.0 \mathrm{IU}$ of antibody per $\mathrm{ml}$. The cut off in the anti-HBc assays was calculated as the mid-point of the means of negative and positive controls. Sera were considered to show evidence of past hepatitis B infection if anti-HBs and anti-HBc were both present, the anti-HBc in all cases being at a level close to the positive control serum (Abbott). Weak anti-HBs levels were detected in some patients in the absence of anti-HBc: these were considered to be negative.
One patient was $\mathrm{HBsAg}$-positive throughout the study.

On this basis, the patients were classified for each period as (1) previously exposed to hepatitis B, (2) at risk if they were seronegative at the start of each quadrenium, (3) showing evidence of infection if anti-HBs and anti-HBc were found in the later sample. The results are summarised in Tables 1 and 2 . The mean ages are given for the mid-points of each period, 1973 and 1977 . Of the 53 patients followed between 1971 and 1975, 24 had evidence of previous infection, 26 patients were negative in 1971, but by 1975 , five $(19 \%)$ of these patients at risk had converted serologically. A further three patients must have been infected a short time before collection of the first sample as initially they had no anti$\mathrm{HBs}$, but did have anti-HBc. The follow-up samples were positive for both antibodies. Interestingly the anti-HBc results in two of these cases were close to the cut off in the first sample, but were clearly positive later. If these three patients are included as infections in the first period, the rate becomes $28 \%$ of those at risk. All of the eight patients classified as seroconverting from 1971 to 1975 had maintained both anti-HBs and anti-HBc when retested in 1977. Forty-six patients were followed from 1975-1979; 25 had been infected before 1975. Of the 21 seronegative cases, eight (38\%) converted by 1979 . The difference between the two rates of infection is not statistically significant.

\section{CLINICAL EVIDENCE OF HEPATITIS}

Of the 16 patients who seroconverted for hepatitis $B$ during the study, only one had clinical jaundice the remaining 15 individuals being asymptomatic.

Table 2 Patients studied 1975-79

\begin{tabular}{|c|c|c|c|c|c|}
\hline \multirow[t]{2}{*}{ Category } & \multirow[t]{2}{*}{ No } & \multicolumn{3}{|c|}{ Severity of haemophilia } & \multirow[t]{2}{*}{ Mean age (yr) (range) } \\
\hline & & Severe & Moderate & $\overline{\text { Mild }}$ & \\
\hline $\begin{array}{ll}1 & \text { Infected before } 1975 \\
2 & \text { Seroconverted } \\
3 & \text { No evidence of infection }\end{array}$ & $\begin{array}{r}25 \\
8 \\
13\end{array}$ & $\begin{array}{r}20 \\
8 \\
5\end{array}$ & $\frac{4}{4}$ & $\frac{1}{4}$ & $\begin{array}{lr}26 \cdot 3 & (9-44) \\
20 \cdot 6 & (7-43) \\
25 \cdot 1 & (11-57)\end{array}$ \\
\hline
\end{tabular}

Of the 21 seronegative patients in 1975, 8 became seropositive by 1979 ie $8 / 21(38 \%)$. 


\section{Discussion}

The study reported here is a follow-up to an investigation of haemophiliacs treated at the Edinburgh Haemophilia Centre between 1971 and 1975. ${ }^{10}$ Serum from this former period was available for many of the patients for retesting concomitantly with an extra sample collected in 1979. The initial survey only asessed patients' HBsAg and anti-HBs levels by reversed passive haemagglutination and radioimmunoprecipitation techniques respectively, but in this follow-up study, anti-HBc had been measured. In the initial study evidence of infection included not only those individuals who seroconverted but also those whose antibody level rose by at least 100 -fold during the period of study. In the current report we have only considered patients as showing evidence of infection if they were initially negative for all markers and subsequently became positive by both antibody tests. The possibility that the patients acquired their anti-HBs and anti-HBc by passive immunisation from either cryoprecipitate (particularly as this may be enriched in immunoglobulins compared to plasma) or factor VIII concentrates must be considered. From a previous study, one in a thousand Scottish blood donors ${ }^{12}$ had an anti-HBs level of $1-10 \mathrm{IU} / \mathrm{ml}$ and if a patient received $50 \mathrm{ml}$ of plasma (the volume of one unit cryoprecipitate) from such a donor the immediate post transfusion level would be approximately $0 \cdot 1-$ $0.2 \mathrm{IU} / \mathrm{ml}$. But even a severe haemophiliac is unlikely to receive cryoprecipitate from more than 500 donors per year and if the half-life of infused anti-HBs is one month, then the chance of any of our patients having acquired a detectable passively transfused antibody must be very small. In all cases scored as positive for both antibodies in the first sample, the later samples were also positive and the actual results in good agreement. At most there was a tenfold variation in anti-HBs levels in a four-year period. In total six patients had a weak anti-HBs level in the absence of anti-HBc in one or more samples. These results were discounted as the antibody might have been acquired from their therapy. In total, 11 patients had low levels of anti-HBs but were also clearly anti-HBc positive. Interpretation of these anti-HBs results alone would be difficult, however, the consistent presence of anti-HBc strongly suggests that these antibodies resulted from infection.

Our patients have received almost exclusively SNBTS factor VIII which contains no detectable anti-HBs, unlike some commercial concentrates which have appreciable levels of this antibody ( $R$ Hopkins, personal communication, 1982). As most severe haemophiliacs in the UK are likely to receive commercial concentrates for a significant part of their treatment, a study such as ours would not be possible at other Haemophilia Centres.

It is clear from this study that hepatitis B infection continued to occur throughout the period 1971-79 at an annual rate of approximately $8 \%$ and presumably patients with evidence of immunity were also continuing to have this boosted. As might be expected the rate of conversion is highest amongst young severe haemophiliacs and it is interesting to note that this was despite the predominant use of cryoprecipitate which might be considered to carry a lower risk of transmitting viral infection compared to factor VIII concentrates which are prepared from large plasma pools derived from many hundreds or thousands of donors. ${ }^{6}$ It is interesting that despite the evidence presented here that over half the patients have evidence of previous hepatitis B infection and frequently abnormal liver function tests ${ }^{13}$ none has symptoms referable to chronic liver disease. For the time being HBV will continue to infect haemophiliacs but it is hoped that the risk may decline in the foreseeable future. Firstly since January 1980 all blood donations in Scotland are being screened for HBsAg by radioimmunoassay. Secondly it is possible that hepatitis-free clotting factor concentrates may become available ${ }^{14}$ and thirdly active immunisation against hepatitis $B$ may be introduced. ${ }^{15}$ Mitigating against a future reduction in infection is the fact that the plasma pool size for manufacture of factor VIII is increasing. It is therefore important that studies such as this should continue and we hope to report a further follow-up in due course to include patients who currently do not demonstrate evidence of HBV infection and newly diagnosed haemophiliacs.

\section{Addendum}

Since this manuscript was prepared a paper, Hepatitis and haemophilia therapy in Australia by $\mathrm{Dr}$ KA Rickard and colleagues (Lancet 1982;ii:146) has appeared. The incidence of hepatitis B infection in Australian haemophiliacs treated predominantly with cryoprecipitate was assessed and found to be identical to the incidence we observed in our Scottish patients.

We have gratefully appreciated the assistance of $\mathrm{Dr}$ SH Davies who initiated the project. We wish to thank the staff of the Scottish National Blood Transfusion Service for their help.

\footnotetext{
References

${ }^{1}$ Craske J, Spooner RJD, Vandervelde EM. Evidence for the existence of at least two types of factor VIII associated non B transfusion hepatitis. Lancet 1978;ii: 1051.
} 
${ }^{2}$ Tsiquaye KN, Zuckerman AJ. New human hepatitis virus. Lancet 1979;i:1135-6.

${ }^{3}$ Norkrans G, Widell A, Teger-Nilsson AC, Kjellman H, Frosner G, Iwarson S. Acute hepatitis non-A, non-B following administration of factor VIII concentrates. Vox Sang 1981;41:129-33.

${ }^{4}$ Bamber M, Murray A, Arborgh BAM, Scheuer PJ, Kernoff PBA, Thomas HC, Sherlock S. Short incubation non-A, non-B hepatitis transmitted by factor VIII concentrates in patients with congenital coagulation disorders. Gut 1981;22:854-9.

${ }^{5}$ Glucke DJ, Greenberg HB, Karey NB. Hepatitis antigen detection of infectious blood donors. Lancet 1969;ii:248-9.

${ }^{\circ}$ Hasiba U, Eyster ME, Gill FM, et al. Liver dysfunction in Pennsylvania's multitransfused haemophiliacs. Dig Dis Sci 1980;25:10.

${ }^{7}$ Holsteen V, Skinhoj P, Cohn J. Hepatitis type B in haemophiliacs. Relation to the source of clotting factor concentrates. Scand J Haematol 1977;10.

${ }^{8}$ Burrell CJ, Black SH, Ramsay DM. Antibody to hepatitis B surface antigen in haemophiliacs on long-term therapy with Scottish Factor VIII. J Clin Pathol 1978;31:309.

${ }^{9}$ Hopkins R, Das PC. A tanned cell haemagglutination test for the detection of hepatitis associated antigen and antibody. $\mathrm{Br} J$ Haematol 1973;25:619-29.

${ }^{10}$ Burrell CJ, Parker AC, Ramsay DH, Proudfoot E. Antibody to hepatitis B antigen in haemophiliacs and their household contacts. J Clin Pathol 1974;27:323-5.

" Peutherer JF, MacKay P, Ross R, Stahl S, Murray JK. Use of the hepatitis B core antigen produced in Eschericheria coli in an assay for anti-HBc. Med Lab Sci 1981;38:355-8.

${ }^{12}$ Hopkins R, Ross Barr A, McClelland DBL. Selection of plasma for hepatitis B immune globulin using a low cost radioimmunoassay. Vox Sang 1981;40:6-11.

${ }^{13}$ Stirling ML, Beckett GJ, Percy-Robb IW. Liver function in Edinburgh haemophiliacs: a five-year follow-up.J Clin Pathol 1981;34:17-20.

${ }^{14}$ Prince AM, Stephan W, Brotman B, Van Den Ende MC. Evaluation of the effect of Betapropritdactone/Ultraviolet irradiation (BPL/UV) treatment of source plasma on hepatitis transmission by factor IX complex in chimpanzees. Thromb Haemost 1980;44:138-42.

${ }^{15}$ Szmuness W, Stevens CE, Harley EJ, et al. Hepatitis B vaccine. Demonstration of efficacy in a controlled clinical trial in a high-risk population in the United States. $J$ Med 1980;303:833-941.

Requests for reprints to: Dr CA Ludlam, Royal Infirmary of Edinburgh, Lauriston Place, Edinburgh EH3 9YW, Scotland. 